\title{
Explorando a construção de identidades nas interações entre professor e aluno na aula de língua estrangeira: reflexões para a prática didática
}

\author{
Roberta Ferroni \\ Universidade de São Paulo \\ robertaferronibr@gmail.com \\ Maria Helena Araújo e Sá \\ Universidade de Aveiro \\ helenasa@ua.pt
}

\begin{abstract}
Resumo
O presente artigo propõe-se obter informações sobre o estilo pedagógico de um professor em formação a partir do estudo dos atos de identidade, com os quais os falantes, nas trocas comunicativas, revelam sua identidade e o papel social que almejam alcançar e que são produzidos pelos aprendizes de italiano língua estrangeira na aula de língua. Como referência teórica e metodológica, adotaremos uma abordagem interessada na observação do funcionamento interacional como espaço de mobilização e de construção das competências de linguagem em situações pedagógicas. A análise, realizada com base em macrounidade chamadas passos pedagógico-didáticos, nos permitiu identificar algumas necessidades do professor quanto aos aspectos que ele é capaz ou não de explorar em sala de aula e a consequente construção de planos globais de formação.
\end{abstract}

Palavras-Chave: Atos de identidade. Interação. Formação.

\begin{abstract}
This article studies acts of identity - the linguistic comments with which speakers, in communicative exchanges, reveal their identity and the social role they wish to play - produced in interactions between the teacher and the student, by learners whose mother tongue is typologically similar to the foreign language they are learning. The analysis of the identity roles performed by learners in foreign language classrooms, in relation to the pedagogical approaches, allow us to identify some necessary characteristics of the teacher as to the aspects they are able or unable to explore in the
\end{abstract}


classroom and the consequent construction of global teacher education plans. As the theoretical and methodological framework, we will follow an approach based on references extracted from studies covering the training of foreign language teachers.

Keywords: Acts of identity. Interaction. Teacher Education.

\section{Enquadramento do estudo}

O presente trabalho toma como base a mesma perspectiva metodológica adotada em um estudo realizado por Ellwood (2008), no qual, analisando os dados levantados em uma classe de língua estrangeira $^{1}$ composta por estudantes que possuem uma bagagem linguística diversificada, a autora aponta um conjunto de "atos de identidade", expressão criada por Le Page e Tabouret-Keller (1985) ${ }^{2}$, para indicar os atos linguísticos por meio dos quais os falantes revelam sua própria identidade pessoal, assim como o papel social que desejam alcançar. Ao longo de sua pesquisa, Ellwood (2008) distingue duas tipologias de atos que denomina atos de alinhamento (Acts of Classroom Alignment) e atos de resistência (Acts of Classroom Resistance).

Mediante os atos de alinhamento (Acts of Classroom Alignment), os estudantes, embora manifestem algumas dificuldades na realização da tarefa, simulam um conjunto de intervenções a fim de demonstrar esforço e dedicação e, assim, agradar o professor, fazendo jus ao papel de "bons alunos". São atos de resistência (Acts of Classroom Resistance) aqueles com que os aprendizes recusam aceitar o papel de estudante passivo, e declaram certa hostilidade em relação à atividade ou ao professor. Embora possam provocar dissonância discursiva no interior do cenário educativo, porque interrompem bruscamente a atividade em andamento, esses atos de identidades são "momentos chave", dado que os discentes, pondo em discussão a

\footnotetext{
${ }^{1}$ Tratava-se de aprendizes de língua inglesa.

${ }^{2}$ De acordo com os estudos de matriz pós-estruturalista (ver, dentre outros, RAMPTON, 1995), para La Page e Tabouret-Keller (1985) cada indivíduo não teria uma identidade única, mas diversas identidades potenciais, no interior das quais pode deslocar-se ou ser deslocado de acordo com o contexto em que está agindo ou comunicando.
} 
autoridade do professor, defendem seu território como aprendizes ativos e, ao fazer isso, redefinem os respectivos papéis, colocando-se no mesmo plano do professor (ELLWOOD, 2008).

A pesquisa que acabamos de citar, porém, além de ter sido realizada com estudantes cuja língua materna (doravante LM) é muito distante da língua estrangeira (doravante LE), limita-se a descrever o que acontece na aula de língua sem dar aos professores indicações uteis que possam servir para refletir e, portanto, melhorar a própria prática profissional.

Sendo que a identidade é uma construção dinâmica e flexível, formada por um repertório de "papeis" identitários possíveis que mudam de acordo com o contexto em que se está agindo ou comunicando por intermédio primordialmente da língua (ELLWOOD, 2008), com este estudo pretendemos investigar, a partir do ângulo epistemológico da Didática de Línguas (doravante DL), os “atos de identidade utilizados pelos aprendizes de italiano LE nas interações entre professor e aluno". A descrição da forma como os atos de identidade surgem e são geridos nas interações em situação de sala de aula nos permitirá traçar alguns dos elementos invariantes que constituem as formas de trabalhar de um professor em formação, que atua nos Cursos de Italiano no Campus da Universidade de São Paulo $(\text { Brasil })^{3}$, e identificar algumas necessidades quanto aos aspectos que ele é capaz ou não de explorar em sala de aula e a consequente construção de planos globais de formação.

O referencial teórico que dá suporte a esta pesquisa situa-se no âmbito interacionista que remonta a Bakhtin (1977) e a Vygotsky (1987) e considera o processo comunicativo uma influência recíproca coconstruída pelos sujeitos nas suas atividades conjuntas em interação uns com os outros. Isso quer dizer que a sua compreensão terá de passar pela análise das formas comunicativas utilizadas e pela compreensão da sua dinâmica e variabilidade. Essa perspectiva dialógica encontra um forte impulso nos trabalhos elaborados desde os

${ }^{3}$ Os dados que vamos apresentar são tirados de uma pesquisa de PósDoutorado financiada pela Fundação de Amparo à Pesquisa do Estado de São Paulo (processo ${ }^{\circ}$ 2015/12825-09) e supervisionada pela Doutora Araújo e Sá, docente de Didática das Línguas do Departamento de Educação da Universidade de Aveiro. 
anos 90 (CICUREL, 2011; MOORE; SIMON, 2002; PEKAREK, 2002; DABÈNE, 1984), no quadro da sociolinguística interacional e da aquisição das línguas estrangeiras, e interessados na observação do funcionamento interacional como espaço de mobilização e de construção das competências de linguagem em situações pedagógicas, pesquisas essas que serão aqui convocadas numa perspectiva de Didática de Línguas (DL). Entende-se, aqui, por DL uma disciplina de interface que mobiliza saberes de outras disciplinas a partir de interrogações próprias relacionadas com os processos de ensinoaprendizagem das línguas, em múltiplos contextos, considerando os seus fatores mais alargados de regulação (sistemas educativos, formação de professores, ambientes sociais etc.) e que assume uma vocação intervencionista e praxeológica, perspectiva epistemológica explorada por investigadores dessa área na Europa e em Portugal, particularmente na Universidade de Aveiro (vejam-se, dentre outros, ALARCÃO; ARAÚJO E SÁ, 2010; ARAÚJO E SÁ, 2000, 2005; ARAÚJO E SÁ; ANDRADE, 2002). Tal abordagem epistemológica, que é fortemente orientada para a ação, usa a análise dos "passos pedagógico-didáticos" (ARAÚJO E SÁ; ANDRADE, 2002) “enquanto estratégias de formação profissional” (ARAÚJO E SÁ, 2005, p. 5).

Dessa forma, a análise do trabalho interativo dos sujeitos em sala de aula torna-se um ângulo de focalização sobre as atividades sociais que eles realizam em conjunto, ou melhor, sobre o sentido que atribuem a essas mesmas atividades. Os "passos pedagógico-didáticos" (ARAÚJO E SÁ; ANDRADE, 2002) são unidades de análise de natureza eminentemente pedagógica e permitem "caracterizar a história interativa através da situação comunicativo-verbal que construíram os professores e as turmas observadas" (ARAÚJO E SÁ, ANDRADE, 2002, p. 36). Cada passo pedagógico-didático (doravante PP-D) pressupõe um forte grau de coesão pedagógica, de responsabilidade do professor, que, por meio dela, faz progredir a aula e, correlativamente, orienta o processo de ensino-aprendizagem. Os critérios que identificam as fronteiras dos PP-D e que guiaram a análise do nosso corpus são: o tópico, a atividade de linguagem e o formato de participação interativa (ARAÚJO E SÁ; ANDRADE, 2002, p. 37). O tópico é aquilo de que se fala. Trata-se, em termos didáticos, do conteúdo da aula, daquilo que pode ser objeto de aprendizagem pelo aluno. As atividades de linguagem são definidas como "toda aquela 
que é realizada no âmbito das tarefas de aprendizagem, atualizando de alguma forma as planificações dos professores e as propostas dos manuais, resultando assim da articulação entre as intenções dos agentes educativos e o seu comportamento real em situação" (ARAÚJO E SÁ; ANDRADE, 2002, p. 37). Quanto ao formato de participação interativa, Araújo e Sá e Andrade (2002, p. 39) descrevem seis estruturas de participação básicas: interação na qual quer o professor quer o aluno partilham o poder interativo (P/A - A/P); estrutura que ocorre quando o professor desempenha plenamente a sua função de vetor de informação (P-(A)); quando o professor, controlando a interação, questiona os alunos e esses respondem, tomando a palavra (P-ALS/A); quando o professor se dirige a um aluno bem identificado (P-A); o trabalho de grupo A-A (P); o trabalho autônomo em que o aluno se confronta com os documentos (A-TA $(\mathrm{P}))$.

\section{Contexto de estudo: Os cursos de Italiano no Campus da Universidade de São Paulo}

Os dados que vamos analisar foram levantados nos cursos de Italiano no Campus, cursos semestrais, destinados à população universitária da Universidade de São Paulo (Brasil) ${ }^{4}$. A presente pesquisa fundamenta-se na observação de um grupo-classe ${ }^{5}$ ao longo do segundo semestre de 2013 e emprega os procedimentos disponibilizados pela abordagem etnográfica (ver, por exemplo, HAMMERSLEY, 2006), dado que um dos valores agregados de uma pesquisa etnográfica é a dimensão qualitativa, possível graças à

\footnotetext{
${ }^{4}$ Os cursos de Italiano no Campus são ministrados por professores em préserviço, matriculados nos cursos de pós-graduação da Faculdade de Letras e Filosofia da Universidade de São Paulo. O objetivo principal desses cursos é promover um espaço para a formação de docentes, por meio de várias ações (dentre as quais: reuniões pedagógicas mensais, jornadas semestrais de formação pedagógica, gravações de aulas posteriormente analisadas). Ao mesmo tempo, o professor em pré-serviço pode ter sua própria classe, com a supervisão de um professor mais experiente, o que constitui em um espaço essencial para a experimentação que faz parte da aprendizagem da profissão.

${ }^{5}$ A escolha do grupo-classe dependeu da disponibilidade manifestada pelo professor e pelos estudantes.
} 
observação. As gravações em vídeo foram realizadas pela coordenadora dos cursos de Italiano no Campus.

Trata-se de um estudo de caso (MORGADO, 2012), cujo corpus da pesquisa é composto de um total de nove horas de gravação em vídeo posteriormente transcritas ${ }^{6}$, correspondente a três aulas. O professor observado é Francesco ${ }^{7}$, italiano, graduado na Itália, que, na época da recolha de evidência, lecionava italiano há três anos e frequentando os cursos de pós-graduação do Departamento de Letras Modernas da Universidade de São Paulo. A classe era formada por doze estudantes de nível intermédio/avançado, equivalente ao nível B1/B2 do Quadro Europeu Comum de Referência-QECR (2002), de LM portuguesa na variante do Brasil, com idade entre vinte e sessenta anos.

As atividades analisadas neste estudo serão descritas de maneira mais detalhada no decorrer da análise; por enquanto, é importante observar que o material proposto na aula provinha do método utilizado, Arrivederci 2, da editora Edilingua ${ }^{8}$ que, segundo os próprios autores, baseia-se na abordagem comunicativa. O método,

\footnotetext{
${ }^{6}$ No tocante às convenções de transcrição, foram parcialmente modificadas as convenções propostas por Van Lier (1988):

..., ..., etc.: pausa breve;

$=:$ dois turnos de palavras em sobreposição;

((inc)), ((risos)): o parêntese duplo indica uma parte da conversação incompreensível ou comentários sobre a transcrição, como risos;

-: indica uma interrupção brusca;

$:::$ os dois pontos repetidos por três vezes indicam um som prolongado;

?: entoação ascendente;

!: entoação descendente;

oh: trecho lido;

Professor Francesco: nome fictício do professor;

Sônia, Simone, Janne, Flavia, Regina, Stefani, Larissa, Roberto, Glória, Maria Amélia, Lila, Lígia: nomes fictícios dos estudantes.

${ }^{7}$ Nome fictício do professor.

${ }^{8}$ Edilingua Edizioni é uma editora italiana (romana) que, segundo os próprios autores, publica desde 1996 materiais específicos para o ensino de italiano L2 e LE, de acordo com uma abordagem comunicativa. Dentre os manuais mais difundidos citamos Nuovo Progetto Italiano e Allegro. Essas informações encontram-se no site da editora http://www.edilingua.it/.
} 
publicado em 2012 e atualizado periodicamente, compõe-se de três volumes que abrangem, respectivamente, os níveis A1, A2 e B1 do QECR (2002) e, na época da pesquisa, estava sendo adotado em todas as classes ${ }^{9}$. Além do livro dos estudantes e daquele dos exercícios, eram utilizados materiais elaborados pelo professor ou extraídos de outros manuais de italiano LE.

\section{Método}

Nesta parte, vamos descrever os procedimentos metodológicos que utilizamos para analisar as interações levantadas na aula de LE.

Após termos concluído as gravações das aulas e a respectiva transcrição, dedicamo-nos ao estabelecimento dos PP-D de que se compunha cada aula. Essa macrounidade de análise nos permitiu obter uma visão rápida do modo como cada aula se desenrolava: as atividades realizadas, os conteúdos que foram trabalhados em termos de competência de linguagem e/ou de aprendizagem e as estruturas de participação em que se organizou o grupo/turma para a construção da comunicação verbal. Além disso, possibilitou ver, de imediato, quantos e quais foram os passos em que cada aula estava dividida e identificar cada ato de identidade, de forma clara e concreta, no âmbito da progressão pedagógico-didática da aula que essa macrounidade nos permite desvendar.

Posteriormente, para identificar e descrever os atos de identidades, efetuamos as microanálises dos fenômenos conversacionais que regulam o formato típico da interação didática, isto, a alternância dos turnos e as duplas adjacentes formadas pelas perguntas iniciadas pelo professor e seguidas pelas repostas dos aprendizes (ORLETTI, 2000; SINCLAIR; COULTHARD, 1975).

Partindo do pressuposto de que os aprendizes, na aula de língua, devem respeitar um conjunto de obrigações, ou seja, falar e compreender em LE (CICUREL, 2011; MOORE; SIMON, 2002), sob

\footnotetext{
${ }^{9}$ A escolha do manual é efetuada em uma reunião colegial de que participam o coordenador dos cursos de Italiano no Campus, docente do Departamento de Letras Modernas da Faculdade de Letras e Filosofia da Universidade de São Paulo, e os professores em pré-serviço.
} 
pena de "sanções" (LAUGA-HAMID, 1990, p. 56, tradução nossa), apontamos os atos de identidade produzidos por aprendizes de italiano nas interações que acontecem entre professor e aluno na aula de LE, de acordo com dois critérios principais: os atos por meio dos quais os aprendizes respeitam as obrigações impostas pelo professor a fim de reivindicarem seu papel de aprendizes; os atos por meio dos quais os estudantes "desritualizam", ou seja, retiram a dimensão ritual do cenário imposta pelo professor a fim de reivindicarem seu próprio papel de "eu"- sujeito.

Visto que, no decorrer da microanálise, muitos atos identificados tendiam a se repetir, a fim de evitar a redundância selecionamos para cada tipo de ato um único exemplo.

\section{Microanálise dos atos de identidade}

No decorrer das aulas do professor Francesco, identificamos, de acordo com os dois critérios descritos acima, quatro tipologias de atos de identidade, que chamamos os "atos para apresentar-se como estudantes exemplares" (24 ocorrências), os "atos de dependência" (20 ocorrências), os "atos de ironia" (10 ocorrências) e os "atos de participação" (2 ocorrências). A seguir, cada um dele será descrito e analisado em relação ao contexto de interação.

\subsection{Os atos para apresentarem-se como estudantes exemplares}

Os atos que denominamos atos para apresentarem-se como "estudantes exemplares" (ELLWOOD, 2008) se verificam em concomitância com as atividades de prática/treino (exercícios estruturais, exercícios lacunares, construção de frases), seguidas de atividades de reflexão/avaliação (identificação e correção de erros) ${ }^{10}$. Trata-se de

${ }^{10}$ Araújo e Sá; Andrade (2002, p. 38) identificam quatro grandes grupos de atividades: as atividades de comunicação/produção(C/P) que servem para por à prova as próprias competências comunicativo-discursivas, como, por exemplo, os debates, as atividades de narração, a exposição oral de fatos pessoais; as atividades de reflexão/avaliação (R/A) cuja finalidade é refletir sobre o funcionamento da língua que é objeto de estudo (por exemplo, 
atividades que têm o objetivo de treinar a competência linguística por meio de exercícios repetitivos e que, conforme as circunstâncias, podem estar associados à competência linguística ou à competência comunicativa $^{11}$. Realizam-se mediante as respostas dos aprendizes às perguntas iniciadas pelo professor (ORLETTI, 2000; SINCLAIR; COULTHARD, 1975) e ocorrem, sobretudo, no formato interativo PALS/A, no qual o professor controla a interação e decide as intervenções dos estudantes. Veja-se a sequência 1, na qual o professor pede que os estudantes façam uma atividade de prática/treino que consiste na construção de frases para treinar o uso do pronome "ci".

Exemplo $1^{12}$

1Professor Francesco: ok facciamo l'esercizio dopo che è abbastanza facile pagina 156 bisogna semplicemente capire se il ci se uso il ci se lo uso come luogo o come altri usi ((lendo)) sara ha provato a fare la torta pasqualina bisogna trasformarlo con il ci e decidere lo facciamo insieme se è

exercícios de identificação e de correção de erros); as atividades de prática/treino (P/T), que consistem na repetição, memorização e imitação de modelos predefinidos (como ditados e exercícios estruturais); as atividades de interpretação/inferência (I/I) que visam colher os diferentes significados da língua e a compreensão dos diferentes níveis de funcionamento (por exemplos, questionários feitos com base em textos, atividades de associação e de transcrição).

11 Araújo e Sá; Andrade (2002, p. 37) identificam oito competências que podem ser consideradas como conteúdo da interação pedagógica observada, são elas: linguística (CL); referencial (CR); pragmática (CP); sociocultural (CSC); discursiva (CD); estratégica (CE); comunicativa (CC) e de aprendizagem (CA).

${ }^{12}$ Tradução: 1Professor Francesco: ok vamos fazer o exercício depois que é bem fácil pagina 156 precisa simplesmente entender se o $c i$ se uso o $c i$ se o uso como lugar ou como outros usos ((lendo)) sara tentou fazer o bolo pascal precisa modificá-lo com o ci e definir vamos fazer juntos se é lugar ou se é outros usos ((lendo)) sara tentou fazer o bolo pascal? 2Larisse: tentou fazê-lo 3Professor Francesco: muito bem sara tentou fazê-lo 4Sônia: outros usos 5Professor Francesco: outros usos fácil matteo vem a roma todos os meses ((lendo)) 6Turma: aqui vem 7Professor Francesco: matteo aqui vem todos os meses neste caso é 8Turma: lugar. 
Explorando a construção de identidades...

luogo o se è altri usi ((lendo)) sara ha provato a fare la torta pasqualina?

2Larisse: ci ha provato

3Professor Francesco: bravissima sara ci ha provato

4Sônia: altri usi

5Professor Francesco: altri usi facile matteo viene a roma ogni mese ((lendo))

6Classe: ci viene

7Professor Francesco: matteo ci viene ogni mese in questo caso è

8Classe: luogo

Os atos para apresentar-se como "estudantes exemplares" (turnos 2, 4, 6, 8) são estimulados não somente pelo formato interativo P-ALS/A, mas também pelas atividades de linguagem, dado que surgem, geralmente, durante a realização de exercícios estruturais de prática/treino, que consistem na reprodução e transformação de frases. Nesse contexto o "eu"-aprendiz tende a prevalecer sobre o "eu"-sujeito pessoa sendo que os aprendizes sentem-se obrigados, sob pena de "sanções" (LAUGA-HAMID 1990, p. 56, tradução nossa), a executar um conjunto de "obrigações" (CICUREL, 1990, tradução nossa) que lhes são impostas para que demonstrem suas competências linguísticas em LE.

\subsection{Os atos de dependência}

Indicamos como "atos de dependência" aqueles em que os estudantes, talvez por causa do formato interativo P-ALS/A, adotam atitudes de dependência excessiva em relação ao professor, mesmo quando, dada a proximidade entre as línguas, não haveria aparentemente necessidade ${ }^{13}$. Geralmente, contêm um pedido de esclarecimento iniciado pelos estudantes, seguido pela resposta do professor, como se vê na sequência 2. O professor só esporadicamente vale-se da colaboração dos estudantes e prefere resolver sozinho, mediante um conjunto de operações informativas metadiscursivas

\footnotetext{
${ }^{13}$ Sobre as vantagens dos estudantes decorrentes da aprendizagem de línguas afins, ver a abordagem baseada na intercompreensão entre línguas românicas (MORDENTE; FERRONI, 2015).
} 
(DABÈNE, 1984, p. 42) $)^{14}$, as dúvidas de natureza referencial manifestadas pelos alunos. Os "atos de dependência" podem manifestar-se no decorrer das atividades de interpretação/inferência, comunicação/produção, prática/treino e reflexão/avaliação e aumentam de maneira exponencial no formato de participação interativo do tipo P-ALS/A.

As respostas às dúvidas manifestadas pelos estudantes são sequenciais, ou seja, ocupam o segundo turno e são formuladas por meio de conjunto de estratégias, como paráfrases (turno 4), gestos (turnos 2, 4) e sinônimos (turno 6), atividades que garantem a compreensão dos participantes em LE, mas, em comparação com o uso da tradução em LM, exigem um esforço maior por parte do professor.

Exemplo $2^{15}$

1Janne: cosa è arrendevole? ((indicando o texto))

2 Professor Francesco: vuol dire arrendevole ((fazendo o gesto de alongar-se))

3Stefanie: sporge?

4 Professor Francesco: sporge proprio in questo in questo contesto vuol dire uscire fuori dal sonno no? ((imitando a ação)) che si sporge verso sporgere ok? avete altri buddi di vocabolario?

5Flavia: cos'è qual- qualunque?

6 Professor Francesco: qualunque? allora..., sarebbe eh:.: non hai mai sentito ovunque dovunque qualunque può essere qualsiasi

\footnotetext{
${ }^{14}$ As informações metadiscursivas aparecem com frequência como resposta a uma pergunta dos estudantes e servem ao professor para transmitir um conjunto de informações de natureza lexical e metalinguística (DABÈNE, 1984).

${ }^{15}$ Tradução: 1Janne: o que é entregue? ((indicando o texto)) 2 Professor Francesco: quer dizer entregue ((fazendo o gesto de alongar-se)) 3Stefanie: alonga? 4 Professor Francesco: alonga na verdade neste neste contexto quer dizer acordar não é? ((imitando a ação)) que se inclina para inclinar ok? tendes outras dúvidas de vocabulário? 5Flavia: o que é qual- qualquer? 6 Professor Francesco: qualquer? então..., seria eh::: você nunca ouviu em qualquer lugar em todo lugar qualquer pode ser qualquer que seja.
} 
Do ponto de vista didático, os "atos de dependência", apesar de terem como objetivo o aperfeiçoamento ou o sucesso da interação em andamento, dado que servem para preencher lacunas referenciais dos alunos, promovem sequências que interrompem bruscamente o PP-D e diminuem seu ritmo. Em síntese, como mostra o exemplo 2, os "atos de dependência" não são aproveitados pelo discurso da aula para desenvolver competências interacionais dos sujeitos que aprendem, em particular porque o professor, ao fornecer uma resposta pronta e imediata, limita fortemente a iniciativa e, portanto, a participação e a colaboração do restante da classe. Note-se que, nessas circunstancias, não há envolvimento da turma na construção em LE daquilo que foi solicitado.

\subsection{Os atos de ironia}

Para subtrair-se à monotonia dos PP-D que contêm atividades de prática/treino, os alunos lançam mão de "atos de ironia". Esses atos, além de criar uma atmosfera mais descontraída entre os membros do grupo, permitem que os aprendizes se apropridm da língua objeto de estudo e que a usem de maneira menos mecânica, tornando-a significativa para ações que são partes de suas vidas reais e não simplesmente meras repetições de temáticas propostas pelo livro didático. O uso do humor produz uma verdadeira "desritualização do cenário didático" (MOORE; SIMON, 2002, p. 133, tradução nossa), graças à saída momentânea dos alunos do papel de aprendizes de língua para formularem enunciados dirigidos ao "você"-pessoa e não mais ao "você"-aluno.

Veja-se o exemplo 3, no qual, Glória se autosseleciona (turno 10) para interromper a atividade de prática/treino que consiste no tranformação das forma irregulares do imperativo (turno 1 até 9). O gracejo de Glória ${ }^{16}$, além de suscitar o riso do grupo-classe, provoca uma mudança de tópico, de forma que, no turno 12, o assunto será outro, totalmente diferente.

\footnotetext{
${ }^{16}$ A ironia que emerge da fala de Glória provém do fato de que, no período da realização das filmagens, a cidade de São Paulo passava por uma grave seca.
} 
Exemplo $3^{17}$

1 Professor Francesco: ok gli imperativi dei verbi irregolari

((lê no livro $)$ ) andare avere dare dire fare

2Glória: andare vado

3 Professor Francesco: ok vado

4Maria Florinda: avere abbia

5 Professor Francesco: abbia dare? ok e fare?

6Classe: faccia

7 Professor Francesco: faccia

8Maria Amélia: fassi

9 Professor Francesco: faccia come la faccia ((indica o rosto)) sia essere stai stare sappia e venga ((lendo no libro)) 10Glória: che venga la pioggia ((risos))

11 Professor Francesco: che venga la pioggia che venga la pioggia

12Ligia: o dia della prova?

\subsection{Os atos de participação}

Os "atos de participação" acontecem geralmente durante algumas atividades de comunicação/produção cujo objetivo principal é aprimorar a competência comunicativa e são atos com os quais os aprendizes se transformam em sujeitos dialógicos em luta por sua emancipação (FREIRE, 1970, p. 105). Em outras palavras, os alunos, seja por causa da atividade que estão desenvolvendo, seja pelo formato interativo e pelo tópico tratado, sentem-se livres para expressar suas opiniões como pessoas, independentemente das competências linguísticas e comunicativas.

17 Tradução: 1 Professor Francesco: ok os imperativos dos verbos irregulares ((lê no livro)) ir ter dar dizer fazer 2Glória: ir vou 3 Professor Francesco: ok vou 4Maria Florinda: ter tenha 5 Professor Francesco: tenha dar? ok e fazer? 6Turma: faça 7 Professor Francesco: faça 8Maria Amélia: fassi 9 Professor Francesco: faça como a cara ((indica o rosto)) seja ser esteja estar saiba e venha ((lendo no libro)) 10Glória: que venha a chuva ((risos)) 11 Professor Francesco: que venha a chuva que venha a chuva 12Lígia: o dia da prova? 
Um exemplo significativo é constituído pelo debate, atividade frequente na aula de LE (PEKAREK, 2002). No decorrer das aulas de Francesco apresentam-se os debates "pré-definidos", uma atividade que, por ser dirigida pelo docente, limita muito as intervenções discursivas dos alunos (FASEL; PEKAREK; POCHON, 2009). Isso acontece seja devido ao formato interativo P-ALS/A, no qual o professor tende a assumir o papel exclusivo de locutor limitando a circulação da palavra, seja devido à presença excessiva de perguntasteste ou display questions (LONG; SATO, 1983) ${ }^{18}$. As perguntas-teste, em certo sentido, provocam um efeito contrário porque, em lugar de contribuir para reestabelecer uma moldura participativa em nível local, acentuam as diferenças de poder entre os participantes da interação.

No exemplo seguinte, após ter lido junto com a classe um artigo extraído de um jornal sobre as polêmicas suscitadas pela declaração homofóbica do proprietário de uma conhecida empresa italiana produtora de massa alimentícia, Francesco pede para o grupo que expresse seu ponto de vista. A atividade não evolui e o PP-D dura apenas 4 minutos durante os quais o professor ocupa a maior parte do tempo. Alguns estudantes, apesar das duas perguntas fechadas (turnos 5 e 10), fazem algumas tentativas tímidas de intervenção (turnos 4, 7), mas o professor logo encerra a sequência, exercendo um predomínio semântico total (turnos 12).

18 As perguntas-teste ou display questions são perguntas cujo objetivo é controlar os conhecimentos dos estudantes e, por isso, as respostas são conhecida previamente pelo professor (LONG; SATO, 1983). 
Exemplo $4^{19}$

1Professor Francesco: e se voi foste il signor barilla? cosa ne pensate di questo articolo? cosa avreste fatto?

2Lila: pazzo

3Professor Francesco: è pazzo il signor barilla? perché?

4Lila: perché ha detto cose che::: pensi e::: pensi ma non dica ((risos))

5Professor Francesco: se sei un'opinione pubblica non puoi però secondo voi è giusto cioè è::: esagerata come reazione no?

6Classe: sì::

7Sônia: in italia la pasta è una cosa che si usa

8Lila: e la famiglia è tradizionale in italia

9Sônia: è lui è espressione di una::: di una parte de::: società

10Professor Francesco: sì un po'dell'immagine dell'italia no?

11Sônia: una immagine più:::: tradizionale

12Professor Francesco: quindi poi vi mando un altro link di una:: comica italiana che diceva sì ma signor barilla la famiglia che tu rappresenti non esiste da nessuna parte non c'è c'è il padre che lavora:::: a milano la madre vive a trieste i figli vivono in inghilterra l'altro chissà dove quindi

19 Tradução: 1Professor Francesco: e se vocês fossem o sr. barilla? o que vocês pensam deste artigo? o que vocês teriam feito? 2Lila: louco 3Professor Francesco: é louco o sr. barilla? por quê? 4Lila: porque deu coisas que::: pensa e::: pensa mas não diga ((risos)) 5Professor Francesco: se você é uma opinião pública não pode mas segundo vocês está certo isto é::: exagerada como reação não é? 6Classe: sim::: 7Sônia: na itália a massa é uma coisa que se usa 8Lila: e a família é tradicional na itáliaSônia: é ele é expressão de uma::: de uma parte da::: sociedade 10Professor Francesco: sim um pouco da imagem da itália não é? 11Sônia: uma imagem mais:::: tradicional 12Professor Francesco: então depois mando para vocês um outro link de uma::: cômica italiana que dizia sim mas sr. barilla a família que o sr. representa não existe em lugar nenhum não tem tem o pai que trabalha:::: em milão a mãe vive em trieste os filhos vivem na inglaterra o outro sabe-se lá onde então esta ideia de famíllia perfeita não existe ela de fato disse talvez fosse melhor se represente a família na qual todos se amam onde estão estão ok meio dia exato se vocês tiverem dúvidas coisas que tirem o sono podem sempre me mandar um email ((risos)). 
questa idea della famiglia perfetta non esiste lei infatti dice forse è meglio se rappresenti la famiglia in cui tutti si amano dove sono sono ok mezzogiorno esatto se avete dei dubbi cose che non riuscite a dormire potete sempre mandarmi una email ((risos))

\section{No caminho da formação}

Tendo descrito a forma como surgem e são geridos em situação de sala de aula os atos de identidade nas interações entre professor e aluno observadas, neste momento explicitaremos alguns dos elementos invariantes que constituem as formas de trabalhar do professor Francesco, lembrando que esta análise tem como principal intuito delinear um projeto de formação a ser desenvolvido posteriormente, voltado para os professores de LE em pré-serviço e baseado na capacidade de observação da interação didática.

Mais concretamente, pretende-se definir um conjunto de atividades destinadas à obtenção de informações, por parte do professor em formação, sobre o que ocorre no processo de ensino/aprendizagem, mediante o qual será possível delinear "um diagnóstico situacional" (ARAÚJO E SÁ; ANDRADE, 2002) e identificar problemas e modalidades passíveis de resolução.

Assim, constatamos a quase onipresença dos chamados "atos para aparecer estudantes exemplares" no decorrer das atividades de prática/treino, atividades essas que atingem o valor mais elevado no corpus (14 ocorrências). A nosso ver, esses atos estão ligados a uma concepção de aquisição/aprendizagem baseada em processos de repetição e automatização, de inspiracão estuturalista, que dá muita enfase à lingua como um conjunto de estruturas relacionadas ao código e ao seu significado (RICHARDS; RODGERS, 1986). Com relação aos "atos de ironia", como vimos, eles: (1). servem para criar um clima mais informal entre os membros do grupo e aparecem no decorrer de atividades de pratica/treino que, além de serem repetitivas e monótonas, reduzem drasticamente a responsabilidade discursiva dos aprendizes; e (2). permitem que os aprendizes se apropriem da língua objeto de estudo, tornando-a significativa para ações que são partes de suas vidas reais e não simplesmente meras repetições de temáticas 
propostas pelo livro didático. No que diz respeito às formas de participação na aula de LE, Francesco privilegia uma comunicação extremamente controlada pelo professor, como se vê pelo fato de a estrutura predominante ser a de P-ALS/A (31 ocorrências). Assim, é o professor que regula a participação e a intervenção em sala de aula, decidindo quem fala, para quem, sobre o quê, quando, por quanto tempo e como, apesar de ele se preocupar em fazer circular a palavra entre o maior número de intervenientes. Embora a comunicação seja construída em conjunto pelos interactantes, a estrutura P-ALS/A acaba favorecendo certa dominância cognitiva do professor sobre os aprendizes, incentivando a presença excessiva dos atos que chamamos de "dependência"20. Esses atos garantem a compreensão dos participantes, mas, do ponto de vista pedagógico, além de interromperem bruscamente o PP-D, são pouco eficazes para a aquisição/aprendizagem da LE. Com efeito, eles denotam uma tendência por parte do aprendiz a "des-responsabilizar-se" pela sua própria aprendizagem que, na maioria dos casos, é atribuída diretamente no professor, que se torna alvo de pedidos dos alunos que não querem assumir o risco de coparticipar da negociação do saber.

Esse fato poderia apontar para a necessidade de se sensibilizar o professor sobre a importância do uso da LM (DUVERGER, 2009), além de estimular a prática da tradução entre o docente e os estudantes, dado que os exercícios de tradução poderiam promover a fluência translinguística ${ }^{21}$, "cada vez mais relevante no nosso mundo globalizado" (GARCÍA, 2013, p. 366, tradução nossa). Mesmo quando são chamados a expor suas ideias durante atividades de comunicação/produção, estando presente o formato interativo PALS/A, associado a um uso excessivo por parte do professor de perguntas-teste ou display questions, os estudantes acabam reduzindo a

${ }^{20}$ A presencia dos atos de "dependência" podem depender, além do formato interativo, também de outros factores como: a natureza da atividade linguística, os modos de organização do trabalho didático, o papel dos alunos na atividade, a natureza do material de input linguístico.

${ }^{21}$ Prática diferente do assim chamado "code-switching", dado que não se refere a uma alternância ou troca de código, mas ao uso de práticas discursivas que, vistas de uma perspectiva bilíngue, não podem ser facilmente atribuídas a uma ou a outra língua (GARCÍA, 2013, p.363). 
produção dos enunciados, que se limitam, com frequência, a "sì " ou "no", ou à produção de informações pré-estruturadas (PEKAREK, 2002, p. 120).

Se levarmos em conta os atos de identidade produzidos nas interações entre professor e aluno pelos aprendizes cuja LM é tipologicamente próxima da LE, podemos notar que o professor, privilegiando a competência linguística como o grande conteúdo da aula, induz os alunos a realizarem uma produção maciça de atos por meio dos quais o "eu"-aprendiz tende a prevalecer sobre o "eu"-sujeito pessoa. Nos raros PP-D em que se observa uma "desritualização" do cenário didático, os alunos expressam a necessidade de sair de um tipo de atividades altamente previsíveis para adquirir seus papéis de sujeitos discursivos.

\section{Considerações finais}

Diante do pressuposto de que a comunicação verbal é a essência da própria relação pedagógica e de que não é possivel compreender as finalidades, assim como os pressupostos e as orientações educativas fora do entendimento dos usos da linguagem que a constituem, a descrição de como surgem e são geridos em situação de sala de aula os atos de identidade pode ajudar neste momento a refletir sobre a própria formação enquanto professores de LE. Para que os atos de identidades possam se tornar em contexto pedagógico oportunidades, para promover o desenvolvimento das competências interacionais em LE, legitimando desta maneira o recurso a formas verbais em LE cada vez mais próximas da língua objeto de estudo, consideramos importante por parte do professor estimular e enriquecer práticas interlocutivas que suscitem uma palavra mais dinâmica, flexível, coconstruída e cogerenciada, em que o aluno possa ter oportunidade de inscrever movimentos de iniciativa.

Tais atividades verbais exigem, contudo, a introdução de algumas condições pedagógicas e comunicacionais no discurso da aula, nomeadamente no que diz respeito às atitudes para com a língua e a comunicação, ao desenvolvimento de competências pragmáticodiscursivas e estratégicas e à planificação de atividades verbais especificas. Para que isto se torne uma realidade è necessario 
desenvolver nos professores em pré-serviço processos de reflexão metapráxica e de consciencialização, alicerçado em momentos de observação, entendida como "conjunto de atividades destinadas a obter dados e informações sobre o que se passa no processo de ensino/aprendizagem" (ALARCÃO; TAVARES, 1987, p. 103), sobre si próprio, a realidade e a sua interação com ela. Acredita-se que essa observação permitirá ao professor em formação passar de um nível essencialmente descritivo da realidade para outro interpretativo, em que se questionam as escolhas feitas, se teorizam opções concretas e se explicitam os implícitos da ação pedagógica (FREEMAN, 1991). Tudo isso com a intenção de partilhar e descobrir aquilo que Alarcão (2005) chama, na linha de Rubin, "inteligência pedagógica", isto é, um conhecimento novo e sempre renovado que emerge da interação constante entre a teoria e a prática ${ }^{22}$.

\section{Referências}

ALARCÃO, Isabel. Supervisão e desenvolvimento da identidade profissional. Aveiro: Universidade de Aveiro, CIDTFF, 2005.

ALCARÃO, Isabel; ARAÚJO E SÁ, Maria Helena. Linhas estratégicas para o desenvolvimento de políticas de investigação $e$ formação em Didáctica de Línguas. Aveiro: Universidade de Aveiro, LALE, 2010.

ALARCÃO, Isabel; TAVARES, José. Supervisão da prática pedagógica. Uma perspectiva de desenvolvimento e aprendizagem. Coimbra: Livraria Almedina.1987.

\footnotetext{
${ }^{22}$ Esse trabalho de reflexão metapráxica, que será discutido em seminários, levará a identificar e a analisar criticamente os atos de identidade produzidos pelos aprendizes em que eles manifestam maiores dificuldades, assim como aqueles em que alcançam êxitos mais significativos. Com base nos problemas diagnosticados, cada docente poderá propor planos de formação-intervenção personalizados, visando melhorar a qualidade das interações e introduzir as inovações pedagógicas.
} 
ARAÚJO E SÁ, Maria Helena. A interação em didática de línguas: percurso epistemológico de um objeto de investigação. In: Congresso Internacional Linguagem e Interação/ III Colóquio Nacional de Filosofia da Linguagem: Linguagem e Interação. Anais... S. Leopoldo: UNISINOS (editado em CD-ROM), 2005.

ARAÚJO E SÁ, Maria Helena. Percursos em didáctica das línguas da observação da interacção pedagógica às propostas de formação profissional. In: __. (Org.). Investigação em Didáctica $e$ Formação de Professores. Porto: Porto Editora, 2000. p. 119-142.

ARAÚJO E SÁ, Maria Helena; ANDRADE, Ana Isabel. Processos de interação verbal em aula de línguas. Observação e formação de professores. Lisboa: Instituto de Inovação Educacional, 2002.

BANGE, Pierre. A propos de la communication et de l'apprentissage de L2 notamment dans ses formes institutionnelles. Acquisition et Interaction en Langue Étrangère, v. 1, n. 1, p.53-85, 1992.

BAKHTIN, Mikhail. Le marxisme et la philosophie du language. Paris: Minuit, 1977.

CICUREL, Francine. Elements d'un rituel communicatif dans les situations d'enseignement. In: DABÈNE, Louise et al. (Eds.). Variations et rituels en classe de langue. Paris: Hatier, 1990. p. 23-54.

CONSELHO DA EUROPA. Quadro comune europeo di riferimento per le lingue: apprendimento insegnamento valutazione. Firenze: La Nuova Italia-Oxford, 2002.

DABÈNE, Louise. Por une didactique de la variation. In: DABÈNE, Louise et al. (Eds.). Variations et rituels en classe de langue. Paris: Hatier, 1990. p. 8-21.

DABÈNE, Louise. Pour une taxonomie des opèrations mètacommunicatives en classe de langue étrangère. Études de Linguistique Appliquée, v. 55, n. 1, p. 39-46, 1984. 
DUVERGER, Jean. Favoriser l'alternance des langues. Le Français dans le monde, v. 362, n. 1, p. 26-28, 2009.

ELLWOOD, Constance. Questions of classroom identity: what can be learned from codeswitching in classroom peer group talk?. Modern Language Journal, v. 92, n. 4, p.538-557, 2008.

FRARACI, Cinzia et al.. Arrivederci 2. Roma: Edilingua, 2012.

FREEMAN, Diane. To make the tacit explicit: teacher education, emerging discourse, and conceptions of teaching. Teaching and Teacher Education, v. 7, n.5, p. 439-456, 1991.

FASEL, Virginie et al. Identification et observabilité de la competence d'interaction: le désaccrd comme microcosme actionnel. Bulletin Suisse de Linguistique Appliqué, v. 86, n. 1, p.121-142, 2009.

FREIRE, Paulo. Pedagogia do oprimido. Rio de Janeiro, Paz \& Terra, 1970.

GARCÍA, Ofelia. El papel de translenguar en la enseñanza del español en los Estados Unidos. In: DUMITRESCU, Domnita; PIÑAROSALES, Gerado (Eds.). El español en los Estados Unidos: e pluribus unum? Enfoques multidisciplinarios. New York: Academia Norteamericana de la Lengua Español, 2013. p. 353-373.

HAMMERSLEY Martyn. Ethnograph: problems and prospects. Ethnography and Education, v. 1, n.1, p. 3-14, 2006.

LAUGA-HAMID, Marie-Claude. L'implication du sujet dans son apprentissage. In: DABÈNE, Louise et al.(Eds.). Variations et rituels en classe de langue. Paris: Hatier, 1990. p. 59-71.

LE PAGE, Robert Brock; TABOURET-KELLER, Andrée. Acts of identity: creole-based approaches to language and ethnicity. Cambridge: Cambridge University Press, 1985. 
Explorando a construção de identidades...

LONG, Michael; SATO, Charlemagne. Classroom foreigner talk discourse: forms and functions of teacher's question. In: SELINGER, Herbert; LONG, Michael (Eds.). Classroom oriented research in second language acquisition. Rowley: Newbury House, 1983, p. 268286.

MOORE, Danièle; SIMON, Diana Lee. Déritualisation et identité d'apprenants. Acquisition et Interaction en Langue Etrangère, v.16, n. 1, p.1-19, 2002.

MORDENTE, Olga Alejandra; FERRONI, Roberta. Novas tendências no ensino/aprendizagem de línguas românicas e na formação de professores. Editora Humanitas: São Paulo, 2015.

MORGADO, José Carlos. O estudo de caso na investigação em educação. Santo Tirso: De Facto Editores, 2012.

ORLETTI, Franca. La conversazione diseguale: potere e interazione. Roma: Carocci, 2000.

PEKAREK, Simona. Formes d'interaction et complexité des tâches discursives: les activités conversationnelles en classe de L2. In:

CICUREL, Francine; VÉRONIQUE, Daniel. (Orgs.). Discours, action et appropriation des langues. Paris: Publications de la Sorbonne Nouvelle, 2002. p. 117-130.

PEKAREK, Simona. Leçons de conversation: dynamiques de l'interaction et acquisition de compétences discursives en classe de langue seconde. Fribourg: Editions Universitaire, 1999.

RAMPTON, Ben. Crossing: language and ethnicity among adolescent. New York: Longman, 1995.

RICHARDS, Jack; RODGERS, Theodore. Approaches and methods in language teaching. Cambridge: Cambridge University Press, 1986. 
SINCLAIR, John McHardy; COULTHARD, Richard. Towards an analysis of discourse: the English used by teachers and pupils. London: Oxford University Press, 1975.

VAN LIER, Leo. The classroom and the language learner. London: Longman, 1988.

VYGOTSKY, Lev Semënovič. Pensamento e linguagem. São Paulo: Martins Fontes, 1987.

Recebido em: 15/08/2016 Aceito em: 14/11/2016

Title: Exploring the construction of identities in teacher-student interaction in the foreign language classroom: reflections for the pedagogical practice 